\title{
Response to the Editorial: The Effect of Chronic Use of Proton Pump Inhibitors on Gastric Cancer
}

\author{
Moon Kyung Joo ${ }^{\mathrm{a}}$ Jong-Jae Park ${ }^{\mathrm{a}}$ Hoon Jai Chun ${ }^{\mathrm{b}}$ \\ ${ }^{a}$ Division of Gastroenterology, Department of Internal Medicine, Korea University College of Medicine Guro \\ Hospital, Seoul, South Korea; ' Division of Gastroenterology and Hepatology, Department of Internal Medicine, \\ Institute of Digestive Disease and Nutrition, Korea University College of Medicine, Seoul, South Korea
}

We read the letter from Professor Liatos et al. who commented on the need for attention to the chronic use of proton pump inhibitors (PPIs) because of the potential significant risk of gastric cancer, supported by recent solid observational studies. We appreciate Professor Liatos' kind and thoughtful comment, and generally agree with his opinion. After we finished our review article, more robust studies were published and firmly suggested the significant association of PPI with gastric cancer. A Swedish nationwide population-based study suggested that chronic PPI use significantly increased the development of gastric cancer, and this finding was also consistent when stratified according to the indication of PPI use, such as peptic ulcer or gastroesophageal reflux [1]. It was interesting to note that the carcinogenic effect of chronic PPI use was consistent, regardless of its indication in this Swedish study because a previous large-scale, populationbased, nested case-control study in the United Kingdom showed the inconsistent effect of PPI between the "peptic ulcer" indication group and the other indication group such as those with "esophageal" or "gastroduodenal symptoms." The result of this study suggested that increased risk of gastric cancer by chronic PPI use might be mainly caused by the underlying overlooked risk factor in patients with peptic ulcer such as Helicobacter pylori (H. pylori) infection, rather than PPI use itself [2]. Indeed, it is necessary to clarify whether PPI is an independent risk factor of gastric cancer, has synergistic effect with $H$. pylori infection, or is even overestimated by concomitant $H$. pylori infection. Profound acid suppression may accelerate the progression of atrophic gastritis by chronic $H$. $p y$ lori infection [3], but PPI is also able to inhibit the growth of $H$. pylori and its bacterial viability [4].

To reduce the confounding effect by $H$. pylori infection, Cheung et al. recently investigated the carcinogenic effect of long-term PPI use after successful $H$. $p y$ lori eradication by using a large-scale health checkup database, and they showed the significant increase of gastric cancer incidence by chronic PPI use in a doseand duration-dependent manner [5]. This Hong Kong study supported the potential inherent effect of PPI on the gastric carci- nogenesis, which had not been fully elicited in the previous small-sized, case-control studies, although this study also has limitation in that it could not totally eliminate the possibility of past PPI use before $H$. pylori eradication. However, with the accumulation of more robust evidences, the statement concerning the relationship between chronic PPI use and risk of gastric cancer may be changed from "controversy" as we mentioned in our manuscript to "possible" or "probable" in the near future.

\section{Disclosures Statement}

None of the authors have potential conflicts (financial, professional, or personal) that are relevant to this publication.

\section{Author Contribution}

M.K.J. wrote the paper; J.-J.P. and H.J.C. revised the manuscript for critical intellectual content.

\section{KARGER}

(c) 2018 S. Karger AG, Basel
Hoon Jai Chun, MD, $\mathrm{PhD}$, AGAF

Division of Gastroenterology and Hepatology, Department of Internal Medicine Institute of Digestive Disease and Nutrition, Korea University College of Medicine 126-1, Anam-dong 5 ga, Seongbuk-gu, Seoul 02841 (South Korea)

E-Maildrchunhj@chol.com 


\section{References}

1 Brusselaers N, Wahlin K, Engstrand L, Lagergren J: Maintenance therapy with proton pump inhibitors and risk of gastric cancer: a nationwide population-based cohort study in Sweden. BMJ Open 2017;7:e017739.

-2 Garcia Rodriguez LA, Lagergren J, Lindblad M: Gastric acid suppression and risk of oesophageal and gastric adenocarcinoma: a nested case control study in the UK. Gut 2006; 55:1538-1544.
Kuipers EJ, Lundell L, Klinkenberg-Knol EC, Havu N, Festen HP, Liedman B, Lamers CB, Jansen JB, Dalenback J, Snel P, Nelis GF, Meuwissen SG: Atrophic gastritis and Helicobacter pylori infection in patients with reflux esophagitis treated with omeprazole or fundoplication. New Eng J Med 1996;334:10181022.

Saniee P, Shahreza S, Siavoshi F: Negative effect of proton-pump inhibitors (PPIs) on
Helicobacter pylori growth, morphology, and urease test and recovery after PPI removal an in vitro study. Helicobacter 2016;21:143152.

Cheung KS, Chan EW, Wong AYS, Chen L, Wong ICK, Leung WK: Long-term proton pump inhibitors and risk of gastric cancer development after treatment for Helicobacter pylori: a population-based study. Gut 2018; 67:28-35. 